\title{
Design and Development of Filtering Antenna for S-Band Applications with High out-of-band Rejection
}

\author{
Srilakshmi R, Manikandan T
}

\begin{abstract}
In this paper, the design, simulation and fabrication of a filtering antenna is proposed. The filtering antenna structure is, therefore, framed by integrating elements, such as the feed line, parallel coupled resonators and the microstrip patch antenna array. The combined elements are designed for third order Chebyshev band pass filter with a pass band ripple of $0.1 \mathrm{~dB}$ and the integrated structure is more suitable for different $S$-band $(2 \mathrm{GHz}-4 \mathrm{GHz})$ wireless applications. The equivalent circuit model for the proposed filtering antenna structure is analysed and the design procedure of the filter is also presented in detail. The $1 x 2$ rectangular patch antenna array acts both as a radiating element and also as the last resonator of the band pass filter. The proposed filtering antenna structure results in high out-of-band rejection, enhanced bandwidth and a gain of about $209 \mathrm{MHz}$ and $1.53 \mathrm{~dB}$. The fabricated result agrees well with the simulation characteristics.
\end{abstract}

Keywords: Filter design, filtering antenna, out-of-band rejection, patch antenna array, $S$-band.

\section{INTRODUCTION}

To meet the demand of distant communication, the wireless systems operating in various frequency bands like $\mathrm{L}, \mathrm{S}, \mathrm{C}$ and $\mathrm{X}$ need an appropriate antenna array with good radiation characteristics. The microstrip patch antenna array is mostly preferred for different applications due to its characteristics like low profile, less cost, light weight and ease of fabrication. Due to the necessity of high gain, the antenna elements increase and hence, the feeding network gets complicated. The complexity causes unexpected resonances and results in bogus pass bands at unnecessary frequencies. Hence, the resultant fake signals can be removed by cascading a suitable bandpass filter and the patch antenna.

The combination of the filter and antenna into a solitary element helps to attain both filtering and radiating tasks concurrently. Especially, the antenna and the bandpass filter are both found to be significant components in the RF front

Revised Manuscript Received on November 12, 2019

* Correspondence Author

Srilakshmi R*, Research Scholar, Department of ECE, Rajalakshmi Engineering College, Chennai-602105, India.

Email: srilakshu.pravin@gmail.com

Manikandan T, Professor, Department of ECE, Rajalakshmi Engineering College, Chennai-602105, India

Email: manikandan.t@rajalakshmi.edu.in end to transmit or receive signals, select the required frequency band and also to suppress unwanted harmonics. In the earlier situation, antennas and filters were designed and brought together independently and linked with each other via a common reference impedance. Such imperfect matching results in additional transition loss and performance degradation. The combined elements (filter and antenna) therefore, called as filtering antenna, have been analyzed and designed in several ways [1]-[17] which is suitable for different wireless applications.

The authors [1] designed the filtering antenna by introducing four different concepts of electromagnetic structures and also analyzed their performance characteristics. In [2], the double layer stacked circular patch antenna was designed on a thin substrate and they have implemented matrix rotation techniques in the filter design to increase the return loss bandwidth. The authors [3]-[5] introduced different techniques in combining a patch element with the bandpass filter to achieve wider bandwidth and steeper response. In [6]-[7], a novel approach is followed in integrating a radiating element with the coupled line resonators. The authors [8]-[10] proposed the design of a differently shaped radiating patch and combined the structure with the conventional shaped resonator to achieve better pass band characteristics and a steeper roll off rate. The design procedure of the two pole Butterworth filter has been illustrated [11] and the prototype is therefore coupled with the fan shaped patch antenna using defected ground structure. The authors [12]-[14] proposed the novel design of a planar filtering antenna structure by considering the external quality factor. In [15], the last resonator of the filter is substituted by the radiating element which is the patch and they have used a proximity coupling feed to interconnect both the elements. The authors [16] proposed the concept of a simplified real frequency technique for better impedance matching by considering two different example structures. In [17], the authors designed an optimized microstrip structure using 3-pole hair pin resonator and a patch antenna and therefore, achieved optimal bandwidth and ideal return loss value. Even though many research works have been studied previously, however, till now more focus has not been given to the integration of the parallel coupled microstrip bandpass filter with the antenna array. In our previous work [18], we have designed the patch antenna array in series and in the 
corporate fed type and analyzed the gain, return loss plots and their radiation pattern measurements.

In this paper, the procedure of integrating a three pole parallel coupled microstrip bandpass filter with the $1 \times 2$ rectangular microstrip patch antenna array has been proposed. The radiating element which is the rectangular patch array is substituted as the last resonator. The third order $(n=3)$ Chebyshev filter is designed by considering the pass band ripple of about $0.1 \mathrm{~dB}, \mathrm{~F}_{\mathrm{BW}}=3.33 \%$ and external quality factor of the filter $Q_{e 1}^{\prime}=30.978$ and $Q_{e 2}^{\prime}=35.545$. The Chebyshev approach is selected since it shows a definite ripple in the pass band region and could lead to an elevated slope in the stop band region. The proposed 3-pole filtering antenna is designed and fabricated for the centre frequency $\left(\mathrm{f}_{0}\right)$ of $2.4 \mathrm{GHz}$, using a Flame Retardant 4 dielectric substrate having a dielectric constant $\left(\varepsilon_{\mathrm{r}}\right)$ value of 4.4 , $1.6 \mathrm{~mm}$ substrate thickness $(\mathrm{h})$ and loss tangent $(\delta)$ value of 0.02 . The resultant structure is therefore designed and simulated using Ansoft High Frequency Structure Simulator Software (HFSS) which employs the finite element method to solve all 3D EM issues [19]. The proposed design not only resulted in considerable improvement in the bandwidth and gain value but also showed high out-of-band rejection. Our proposed configuration of the filtering antenna is found to be more suitable for present day S-band wireless communication system applications.

Section II clearly explains the design procedure and configuration of the filter, antenna array and filtering antenna equivalent circuit, and the simulated and fabricated results. We have also done a comparison of the proposed work with the other research works mentioned in the survey. Conclusions and future work are discussed in section III.

\section{Design Procedure and Configuration}

\section{A. Model of the filtering antenna}

The configuration and layout of the proposed filtering antenna structure is shown in Fig. 1a and 1b. The filtering antenna contains half wavelength parallel coupled resonators, microstrip line feed and the patch element. The ground plane inserted in the centre is shared by both patch antenna and the filter. Through this configuration, the dimension of the whole structure can be considerably reduced. The elements, antenna and filter, are cascaded to match $50 \mathrm{Ohm}$ impedance. The filter and antenna when united, directly result in impedance mismatch and hence, the performance of the filter gets affected, particularly near the band edges and also tends to increase the circuit's insertion loss. In order to avoid such deterioration, an additional matching network has been implemented between the filter and antenna. The matching network helps to match the quality factor value of the filter and antenna and thus, we were able to achieve a strong coupling between the two elements. We have used a sub-miniature version A (SMA) connector to feed the microwave power to the filtering antenna structure.

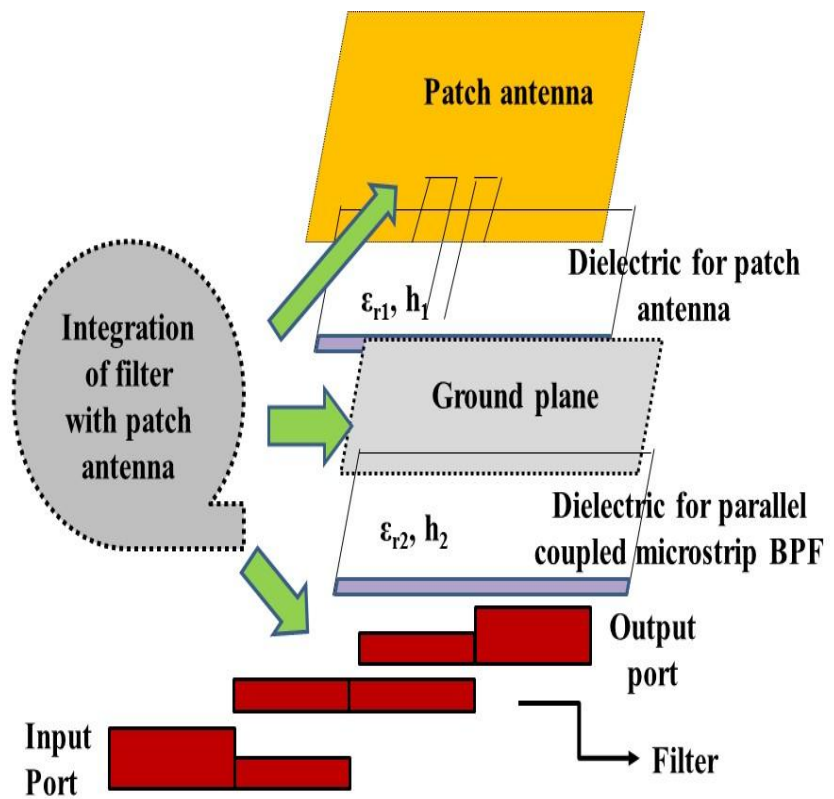

Fig. 1a. Layout of the filtering antenna structure (Top view)

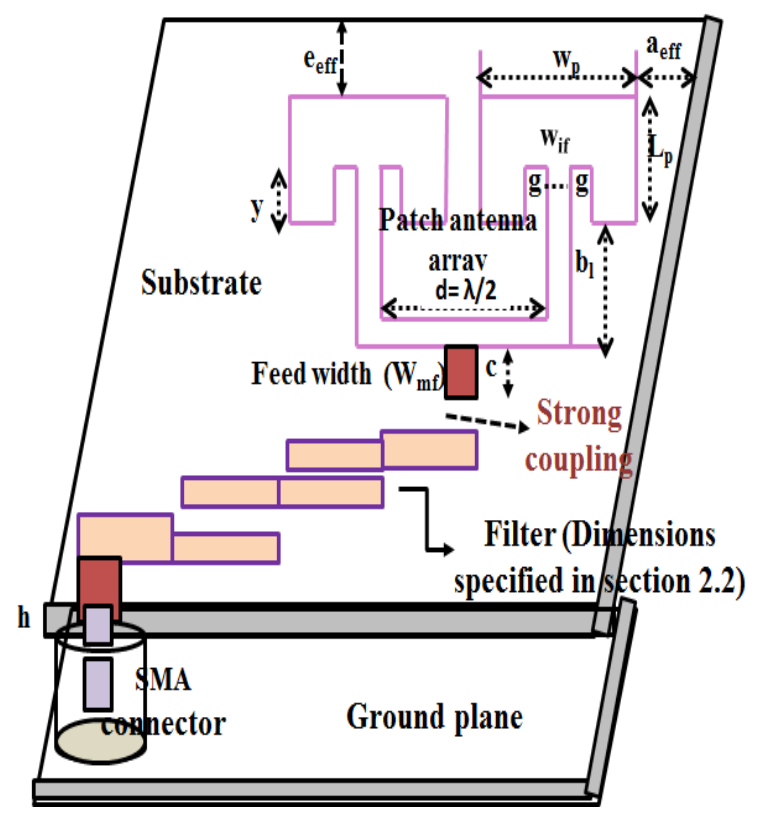

Fig. 1b. Layout of the filtering antenna structure (Front view)

From the results of our previous work [18], we identified that the corporate fed type patch structure resulted in an ideal gain of about $5.43 \mathrm{~dB}$ and bandwidth of $50 \mathrm{MHz}$ at various distance values like $\lambda, \lambda / 2, \lambda / 4$ and so on. Hence, we have extended our work further by integrating the microstrip bandpass filter with the corporate fed type patch antenna array. The design specifications of the patch antenna array are listed in Table I. 
Table- I: Specifications of the corporate fed patch antenna array

\begin{tabular}{|c|c|c|}
\hline Symbol & Quantity & $\begin{array}{c}\text { Values } \\
\text { (mm) }\end{array}$ \\
\hline \multicolumn{3}{|c|}{ Substrate Material: FR4_Epoxy } \\
\hline$\varepsilon_{\mathrm{r}}$ & Dielectric constant & 4.4 \\
\hline $\mathrm{W}_{\mathrm{p}}$ & Patch antenna_Width & 38.04 \\
\hline $\mathrm{L}_{\mathrm{p}}$ & Patch antenna_Length & 29.44 \\
\hline $\mathrm{h}$ & Substrate thickness & 1.6 \\
\hline $\mathrm{g}$ & Feed line and patch element gap & 0.3 \\
\hline $\mathrm{b}_{\mathrm{l}}$ & Feed length & 20.93 \\
\hline $\mathrm{c}$ & 50 Ohms_Inset depth & 10.82 \\
\hline $\mathrm{w}_{\mathrm{mf}}$ & Main feed width_50 Ohms & 2.57 \\
\hline $\mathrm{W}_{\mathrm{if}}$ & 100 Ohms_Feed width & 0.44 \\
\hline $\mathrm{y}$ & 100 Ohms_Inset Depth & 9.04 \\
\hline $\mathrm{d}=\lambda / 2$ & Patch element distance & 62.5 \\
\hline $\mathrm{a}_{\mathrm{eff}}, \mathrm{e}_{\mathrm{eff}}$ & Effective length \& width & 5,5 \\
\hline
\end{tabular}

\section{B. Problem Formulation and Design of Microstrip BPF}

Among various types of filters available, microstrip filters are found to be the good choice as they decrease the complexity of the microwave circuits and the passive elements used in the communication systems. Different dielectric materials like FR4, Teflon and Rogers Duroid are frequently employed as substrates in microstrip filters. The choice of those dielectric materials depends on the required frequency of operation, ease of use and allowed losses. The dielectric constant values and permittivity differ for these materials and hence, their electrical characteristics vary from one another under different operating conditions. Different types of conventional microstrip bandpass filters like hairpin type filter, half wavelength parallel coupled resonators, and stub line are commonly implemented in several $\mathrm{RF} /$ microwave applications [20]. Present day wireless communication systems need broadband wireless access and hence, we have used half wavelength parallel coupled microstrip band pass filters because of their simplicity, ease of fabrication and superior performance. Mathematical analysis and numerical computations are used to design the parallel coupled resonators and the design specifications vary for different applications. Regular assumptions for dielectric substrate thickness, material losses, tangent losses and conductor thickness are considered.

Standard steps are followed for designing and analysing the third order parallel coupled microstrip bandpass filter for the centre frequency $\left(\mathrm{f}_{0}\right) 2.4 \mathrm{GHz}$. The low pass prototype element values for the third order Chebyshev type filter with ripple $0.1 \mathrm{~dB}$ are obtained from the table specified [20]. The element values are $\mathrm{g}_{0}=1, \mathrm{~g}_{1}=C_{1}^{\prime}=1.0316, \mathrm{~g}_{2}=L_{2}^{\prime}=1.1474$, $\mathrm{g}_{3}=C_{3}^{\prime}=1.0316$ and $\mathrm{g}_{4}=1$. The low pass Chebyshev prototype filter element values are further transformed into the corresponding BPF $\mathrm{L}$ and $\mathrm{C}$ components using equations (1) and (2). The filter transformation is achieved by replacing the shunt capacitor with the parallel $\mathrm{L}$ and $\mathrm{C}$ component and the series inductor by the series LC component [20]. Here $50 \Omega$ characteristic impedance $\left(\mathrm{Z}_{0}=1 / \mathrm{Y}_{0}\right)$ is assumed for connecting the input and output resonator feed lines.

$$
\begin{gathered}
C_{p 1}=\frac{C_{1}^{\prime}}{Z_{0} F_{B w} 2 \pi f_{0}} \text { and } L_{p 1}=\frac{F_{B w} Z_{0}}{2 \pi f_{0} C_{1}^{\prime}}(1) \\
L_{s 2}=\frac{Z_{0} L_{2}^{\prime}}{F_{B w} 2 \pi f_{0}} \text { and } C_{s 2}=\frac{F_{B w}}{Z_{0} 2 \pi f_{0} L_{2}^{\prime}}(2)
\end{gathered}
$$

The final obtained $\mathrm{L}$ and $\mathrm{C}$ values of the bandpass filter structure are $\mathrm{C}_{\mathrm{pl}}=\mathrm{C}_{\mathrm{p} 3}=41.08 \mathrm{pF}, \mathrm{L}_{\mathrm{p} 1}=\mathrm{L}_{\mathrm{p} 3}=0.10703 \mathrm{nH}$ and $\mathrm{L}_{\mathrm{s} 2}=114.24 \mathrm{nH}, \mathrm{C}_{\mathrm{s} 2}=0.0384 \mathrm{pF}$. After obtaining the required $\mathrm{L}$ and $\mathrm{C}$ element values of the BPF prototype, the next step is to design the parallel coupled microstrip BPF structure using the equations specified below. The first step of the design is to obtain the J-inverter coefficients using equations (3), (4) and (5) and these coefficients help to obtain the characteristic impedance of the even mode and odd mode parallel coupled resonators.

$$
\text { For } \mathrm{i}=0, \frac{J_{0,1}^{\prime}}{Y_{0}}=\left(\sqrt{\frac{\pi}{2} \frac{F_{B W}}{g_{0} g_{1}}}\right)(3)
$$

$$
\text { For } \mathrm{i}=1 \text { to } \mathrm{n}-1, \frac{J_{i, i+1}^{\prime}}{Y_{0}}=\frac{\pi F_{B W}}{2} \frac{1}{\sqrt{g_{i} g_{i+1}}}(4)
$$

$$
\text { For } \mathrm{i}=\mathrm{n}+1, \frac{J_{n, n+1}^{\prime}}{Y_{0}}=\sqrt{\frac{\pi F_{B W}}{2 g_{n} g_{n+1}}}(5)
$$

Where $\mathrm{F}_{\mathrm{BW}}$ is the fractional bandwidth and it is given by the expression $F_{B W}=\frac{f_{2}-f_{1}}{f_{0}}=0.0333 . J_{i, i+1}^{\prime}$ is the characteristic admittance of the J-inverters. The external quality factors of the resonators $Q_{e 1}^{\prime}=30.978$ and $\left(Q_{e 2}^{\prime}\right)=35.545$ are computed using the equation (6).

$$
Q_{e 1}^{\prime}=\frac{g_{0} g_{1}}{F_{B W}} \text { and } Q_{e i}^{\prime}=\frac{g_{i} g_{i+1}}{F_{B W}} \text { for } \mathrm{i}=2 \text { to } \mathrm{n}-1
$$

The next step is to obtain the even mode $Z_{o e}^{\prime}$ and odd mode $Z_{o o}^{\prime}$ impedances using equations (7) and (8).

$$
\begin{aligned}
& \left(Z_{o e}^{\prime}\right)_{i, i+1}=\frac{1}{Y_{0}}\left[1+\frac{J_{i, i+1}^{\prime}}{Y_{0}}+\left(\frac{J_{i, i+1}^{\prime}}{Y_{0}}\right)^{2}\right], \text { for } \mathrm{i}=0 \text { to } \mathrm{n}(7) \\
& \left(Z_{o o}^{\prime}\right)_{i, i+1}=\frac{1}{Y_{0}}\left[1-\frac{J_{i, i+1}^{\prime}}{Y_{0}}+\left(\frac{J_{i, i+1}^{\prime}}{Y_{0}}\right)^{2}\right], \text { for } \mathrm{i}=0 \text { to } \mathrm{n}(8)
\end{aligned}
$$

The calculated $\mathrm{J}$ inverter coefficients, and the even mode and odd mode impedance values for different values of 'i' are specified in Table II. 
Table- II: Calculated coefficients of the filter

\begin{tabular}{|c|r|c|c|}
\hline $\begin{array}{c}\text { Order of the } \\
\text { filter 'n' for } \\
\text { different } \\
\text { values of 'i' }\end{array}$ & $\begin{array}{c}\text { J inverter } \\
\text { coefficients } \\
\boldsymbol{J}_{\boldsymbol{i , i + 1} \mathbf{1}}^{\prime} / \boldsymbol{Y}_{\mathbf{0}}\end{array}$ & $\begin{array}{c}\text { Even mode } \\
\text { impedance } \\
\text { Values } \boldsymbol{Z}_{\boldsymbol{o}}^{\prime}\end{array}$ & $\begin{array}{c}\text { Odd mode } \\
\text { impedance } \\
\text { Values } \boldsymbol{Z}_{\text {oo }}^{\prime}\end{array}$ \\
\hline 0 & 0.22517 & 63.794 & 41.277 \\
\hline 1 & 0.04807 & 52.519 & 47.712 \\
\hline 2 & 0.04807 & 52.519 & 47.712 \\
\hline 3 & 0.22517 & 63.794 & 41.277 \\
\hline
\end{tabular}

Using the even mode and odd mode impedance values specified above, the subsequent step is to find the dimensions of the coupled microstrip lines like width ' $\mathrm{W}_{\mathrm{i}}$ ' and space ' $\mathrm{G}_{\mathrm{i}}$ ' and length ' $\mathrm{L}_{\mathrm{i}}$ '. Using equations (9) and (10), the spacing gap ' $\mathrm{G}_{\mathrm{i}}$ ' between the resonators and width ' $\mathrm{W}_{\mathrm{i}}$ ' can be calculated.

$$
\begin{gathered}
\frac{G_{i}}{h} \\
=\left\{\frac{2}{\pi} \cosh ^{-1}\left[\frac{\cosh \left(\frac{\pi}{2}\right)\left(\frac{w}{h}\right)_{s e}+\cosh \left(\frac{\pi}{2}\right)\left(\frac{w}{h}\right)_{s o}-2}{\cosh \left(\frac{\pi}{2}\right)\left(\frac{w}{h}\right)_{s o}-\cosh \left(\frac{\pi}{2}\right)\left(\frac{w}{h}\right)_{s e}}\right]\right\}(9) \\
\frac{W_{i}}{h}=\left\{\frac{1}{\pi}\left[\cosh ^{-1} 0.5((p)+(q) *(r))-\frac{\pi}{2} \frac{G_{i}}{h}\right]\right\}
\end{gathered}
$$$$
\text { for } \mathrm{i}=1,2 . \mathrm{n}(10)
$$

Where $p=\cosh \left(\frac{\pi}{2} \frac{G_{i}}{h}\right)-1, q=\cosh \left(\frac{\pi}{2} \frac{G_{i}}{h}\right)+1$ and $r=\cosh \left(\frac{\pi}{2}\right)\left(\frac{w}{h}\right)_{s e}$.

Here, $(w / h)_{s e}$ and $(w / h)_{s o}$ are obtained by applying the even mode and odd mode impedance values to the single microstrip lines and $h$ is the height of the substrate. Its calculated dimensions are specified in Table III.

Table- III: Dimensions of $(w / h)_{s e}$ and $(w / h)_{s o}$

\begin{tabular}{|c|c|c|}
\hline $\begin{array}{c}\text { For different } \\
\text { values of ' } \mathbf{i} \text { ' }\end{array}$ & $(\boldsymbol{w} / \boldsymbol{h})_{\boldsymbol{s e}}$ & $(\boldsymbol{w} / \boldsymbol{h})_{\boldsymbol{s o}}$ \\
\hline 0 & 3.8072 & 7.2836 \\
\hline 1 & 5.0623 & 5.8014 \\
\hline 2 & 5.0623 & 5.8014 \\
\hline 3 & 3.8072 & 7.2836 \\
\hline
\end{tabular}

Using the above values in equations (9) and (10), the final dimensions of width ' $\mathrm{W}_{\mathrm{i}}$ ', spacing ' $\mathrm{G}_{\mathrm{i}}$ ' are obtained and length $\mathrm{L}_{\mathrm{i}}$ of the parallel coupled microstrip BPF are obtained using equation (11). The obtained values are specified in Table IV. The dimensions are further optimized to improve the performance of the filter and also for ease of fabrication. Hence, we have slightly adjusted the spacing gap between the resonators as $\mathrm{G}_{1,4}=0.2$ and $\mathrm{G}_{2,3}=1.1$.
Table- IV: Calculated and final optimized dimensions of Parallel coupled BPF in ( $\mathrm{mm})$

\begin{tabular}{|c|c|c|}
\hline Parameters & $\begin{array}{c}\text { Calculated } \\
\text { dimensions of } \\
\text { the BPF }\end{array}$ & $\begin{array}{c}\text { Optimized } \\
\text { dimensions of the } \\
\text { BPF }\end{array}$ \\
\hline $\mathrm{W}_{1}, \mathrm{~W}_{4}$ & 2.98159 & 2.98 \\
\hline $\mathrm{L}_{1}, \mathrm{~L}_{4}$ & 17.142 & 17.14 \\
\hline $\mathrm{G}_{1}, \mathrm{G}_{4}$ & 0.133 & 0.2 \\
\hline $\mathrm{W}_{2}, \mathrm{~W}_{3}$ & 3.5973 & 3.6 \\
\hline $\mathrm{L}_{2}, \mathrm{~L}_{3}$ & 17.0096 & 17.01 \\
\hline $\mathrm{G}_{2}, \mathrm{G}_{3}$ & 1.28761 & 1.1 \\
\hline $\mathrm{L}_{50 \Omega}$ & 17.01 & 17.01 \\
\hline
\end{tabular}

The length ' $\mathrm{L}_{\mathrm{i}}$ ' of the coupled line resonator at every stage is computed using the expression,

$$
L_{i}=\frac{\lambda}{4 \sqrt{\varepsilon_{r e}}}
$$

Where $\lambda=\mathrm{c} / \mathrm{f}_{0}, \mathrm{c}$ is the velocity of light in $(\mathrm{m} / \mathrm{sec})$ and

$$
\varepsilon_{r e}=\frac{\varepsilon_{r}+1}{2}+\frac{\varepsilon_{r}-1}{2}\left(\frac{1}{\sqrt{1+\left((12 * h) / W_{i}\right)}}\right)
$$

The dimensions obtained are rounded off and the resultant layout of the three pole parallel coupled microstrip BPF is illustrated in Fig. 2.

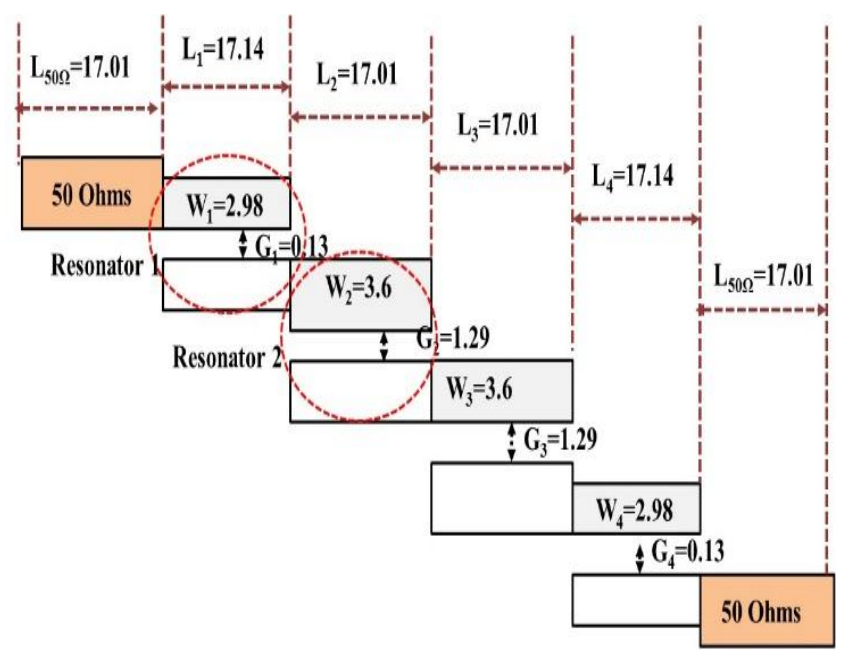

Fig. 2. Microstrip layout of the third order Parallel Coupled Microstrip BPF

The simulated return loss plot for the calculated and optimized dimensions of the filter is shown in Fig.3. The plots show a fine frequency response with their return loss value $\mathrm{S} 11$ for the calculated dimensions (solid line) reaching $-29.27 \mathrm{~dB}$ at $2.27 \mathrm{GHz}$ and $-19.72 \mathrm{~dB}$ at $2.38 \mathrm{GHz}$. Insertion loss which is $\mathrm{S} 21$ for the calculated dimensions (solid line) is $-3.2 \mathrm{~dB}$ and the bandwidth of 
the filter is approximately found to be $280 \mathrm{MHz}$ (from 2.166 to $2.446 \mathrm{GHz}$ ). For the optimized filter dimensions (dashed line), it is found that, the return loss $\mathrm{S} 11$ got reduced which is $-20.65 \mathrm{~dB}$ at $2.28 \mathrm{GHz}$ and $-15.35 \mathrm{~dB}$ at $2.43 \mathrm{GHz}$. Insertion loss $\mathrm{S} 21$ is $-2.86 \mathrm{~dB}$ and the bandwidth of the filter is gradually increased to about $340 \mathrm{MHz}$ (from 2.14 to 2.48 $\mathrm{GHz}$ ). Hence, we have continued our work with the optimized filter dimensions.

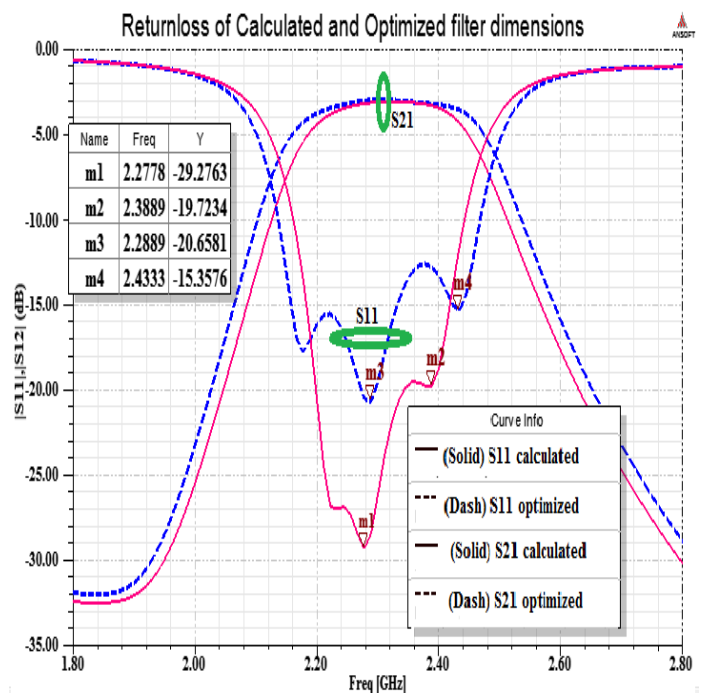

Fig. 3. Comparison of the simulated S Parameters of $\mathrm{BPF}$

The next step is to design the structure of the filtering antenna, and that is obtained by integrating the parallel coupled microstrip BPF with the patch antenna.

\section{Equivalent circuit model of the proposed filtering antenna structure and simulation results}

The equivalent circuit of the proposed filtering antenna structure is shown in Fig. 4. A single rectangular microstrip patch antenna is represented by the parallel combination of the $\mathrm{R}_{1}, \mathrm{~L}_{1}$ and $\mathrm{C}_{1}$ circuit [21]-[23].
The resonant frequency of the patch is determined by the $\mathrm{L}_{1}$ and $\mathrm{C}_{1}$ components. The pair of slots incorporated into the rectangular patch structure of dimension $\mathrm{g}=0.3 \mathrm{~mm}$ increases the bandwidth and the second resonant frequency is determined using the $\mathrm{L}_{2}$ and $\mathrm{C}_{2}$ components. Similarly, the parameters of the second patch antenna are represented by $R_{1}^{\prime}, L_{1}^{\prime}, C_{1}^{\prime}$ and $R_{2}^{\prime}, L_{2}^{\prime}, C_{2}^{\prime}$. The microstrip line feed is designed for the impedance $50 \Omega$ and it connects the radiating patch elements. The microstrip line feed can be represented as an equivalent $\mathrm{T}$ - shaped structure [24] containing capacitor $\mathrm{C}_{0}$, strip inductance $\mathrm{L}_{0}$ and patch inductance $\mathrm{L}_{\mathrm{p}}$. Both, the half wavelength parallel coupled resonators and the antenna array are integrated using the coupling capacitor $\mathrm{C}_{\mathrm{C}}$. The dimensions of the filter and their parameters have already been described in section $\mathrm{B}$.

Initially, we had started our work by integrating the single patch antenna with the parallel coupled microstrip BPF and the summary of our analysed results is specified in Table $\mathrm{V}$.

Table- V: Single patch element and BPF

\begin{tabular}{|l|c|c|c|}
\hline Element & Return loss & Bandwidth & Gain (dBi) \\
\hline $\begin{array}{c}\text { Single patch } \\
\text { without BPF }\end{array}$ & $-23 \mathrm{~dB}$ & $70 \mathrm{MHz}$ & 3.29 \\
\hline $\begin{array}{c}\text { Single patch } \\
\text { with BPF }\end{array}$ & $-25 \mathrm{~dB}$ & $180 \mathrm{MHz}$ & 0.6 \\
\hline
\end{tabular}

Through our analysis, we identified that, the integration of the filter and single patch element suppressed the unwanted frequency band apart from the required frequency which is $2.4 \mathrm{GHz}$. We also observed that the bandwidth of the filtering antenna structure is increased by about 2.5 times more when compared to the structure designed without the filter. From our simulated plot, we came to know that, the slight mismatch during interconnection resulted in the degradation on band edge selectivity and also found that, the gain value got considerably decreased which is less than 1 dB.

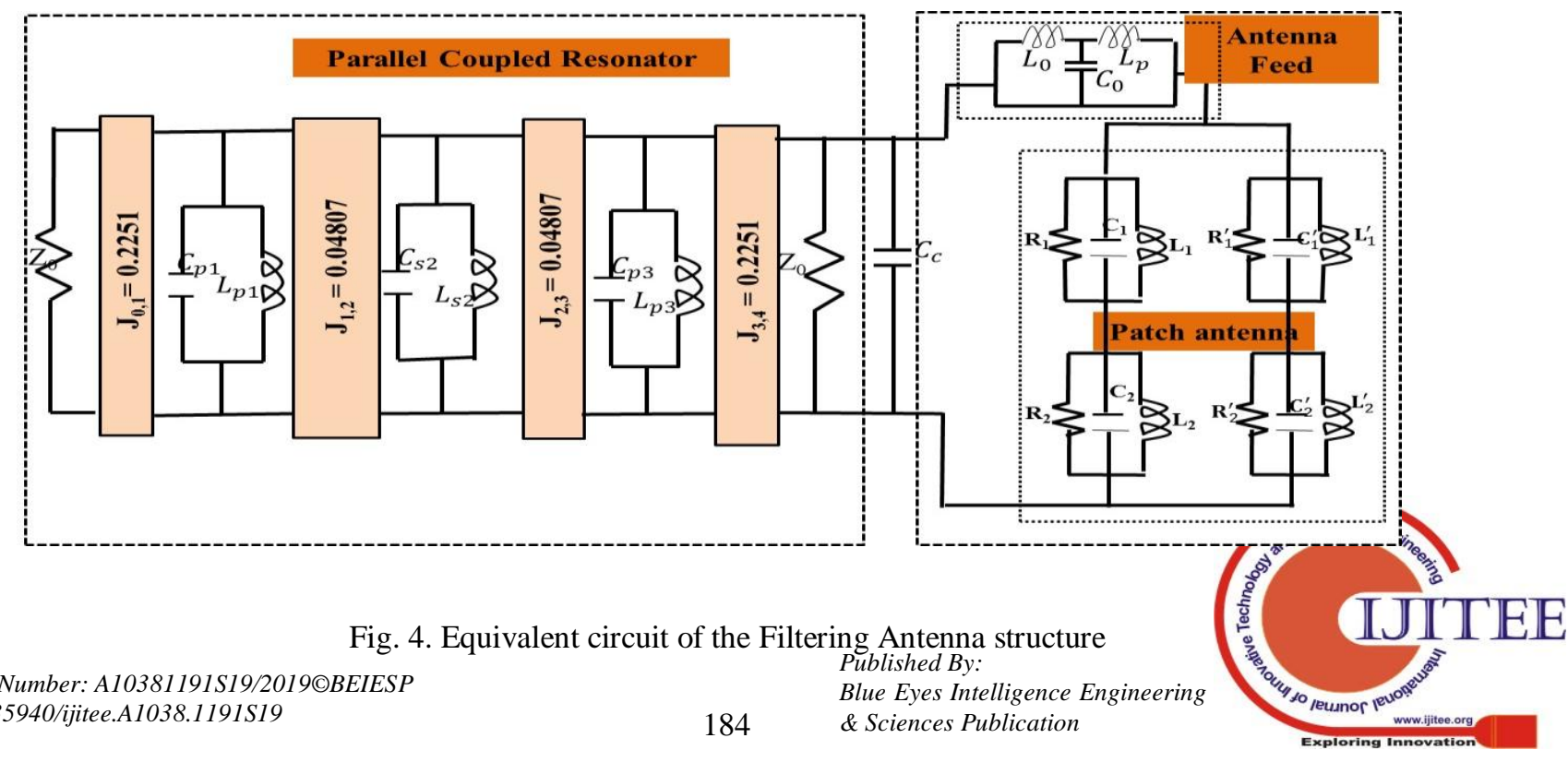


Hence, such problems can be surmounted by using the array of microstrip patch elements. So, we have replaced the single patch antenna with the array of patch (1x2) elements which act as the last resonator of the BPF. The dimensions of the proposed filtering antenna structure are $\mathrm{L}_{\mathrm{p}} \mathrm{x} \mathrm{W}_{\mathrm{p}}$ is $170 \mathrm{~mm} \mathrm{x}$ $93 \mathrm{~mm}$. The designed structure is simulated and the comparison plot is shown in Fig. 5 for the patch element array without band pass filter and the antenna array with band pass filter.

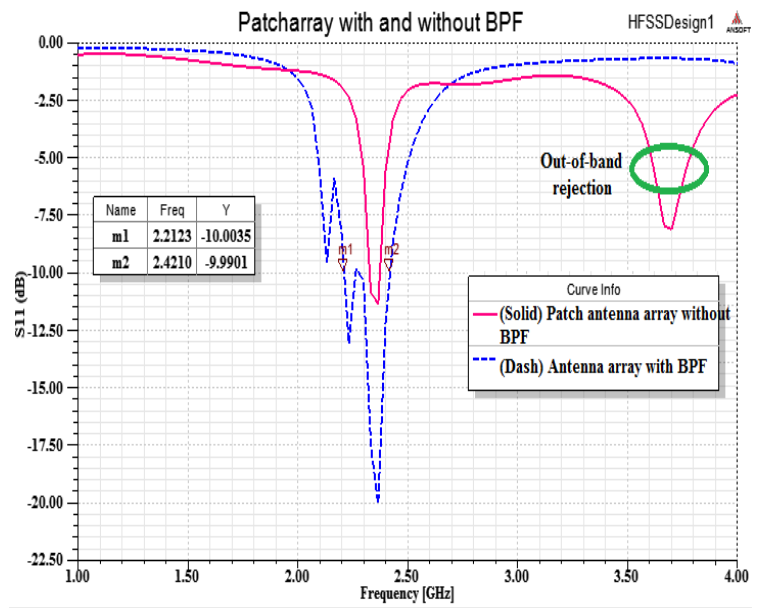

Fig. 5. Return loss plot for patch antenna array with and without BPF

For, the patch antenna array without BPF (Solid line), we were able to attain the bandwidth of about $50 \mathrm{MHz}$ [18]. The value of the quality factor of the patch element array is $\mathrm{Q}_{\mathrm{f}}$ (patch array) $=\mathrm{f}_{0} / \Delta \mathrm{f}=48$. The integration of filter and antenna is done in such a way that, their external quality factor values are comparatively matched. Compared to the patch antenna array, the proposed filtering antenna structure (Dashed line) eliminates an unwanted frequency band which is $3.75 \mathrm{GHz}$ and also resulted in the enhanced bandwidth of about 209 MHz. The combined structure shows fine characteristics with the return loss value of about $-20 \mathrm{~dB}$ at $2.36 \mathrm{GHz}$. The impedance mismatch during interconnection results in a maximum return loss value at the passband of about $-9.77 \mathrm{~dB}$ at $2.26 \mathrm{GHz}$ and $-5.89 \mathrm{~dB}$ at $2.16 \mathrm{GHz}$.

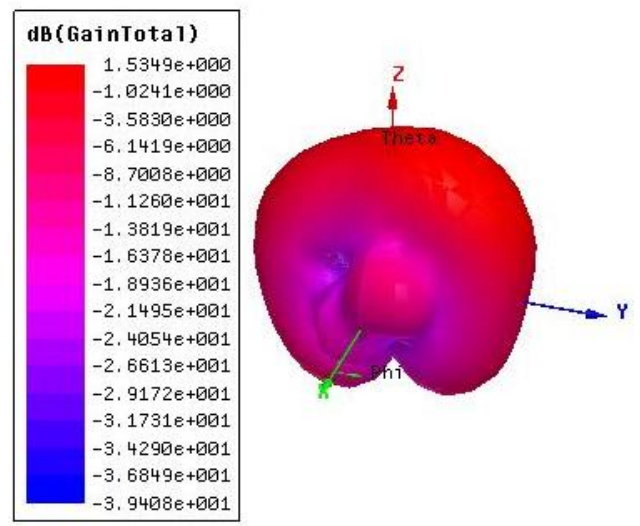

Fig. 6. Gain plot of the proposed filtering antenna
The obtained gain value and the directivity of our proposed structure is about $1.53 \mathrm{~dB}$ [Fig. 6] and $9.63 \mathrm{~dB}$. The E-plane and $\mathrm{H}$-plane far field radiation pattern of our proposed structure [Fig. 7] is simulated for different values of theta $\left(0^{0}\right.$ to $\left.360^{\circ}\right)$ and phi $\left(0^{\circ}, 90^{\circ}\right)$ for the centre frequency $2.4 \mathrm{GHz}$. We have observed a unidirectional pattern in both the $\mathrm{xz}$ and yz planes. The HPBW for the E-plane radiation pattern is approximately about $342^{0}$.

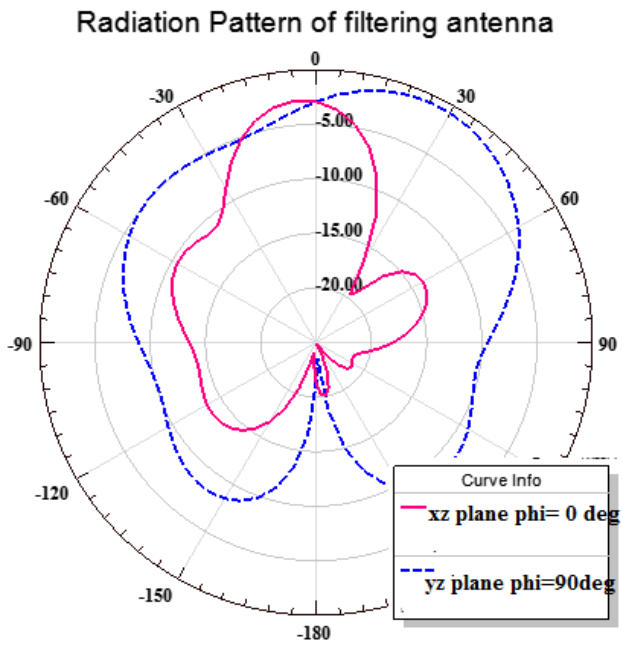

Fig. 7.Radiation Pattern

The impedance matching characteristics of the filtering antenna structure at the desired frequency points are illustrated in Fig. 8. From the plot, we inferred that, a perfect matching of $47.25 \mathrm{Ohms}$ is observed at $2.398 \mathrm{GHz}$. Thus, through our proposed structure, we were able to achieve a good impedance matching.

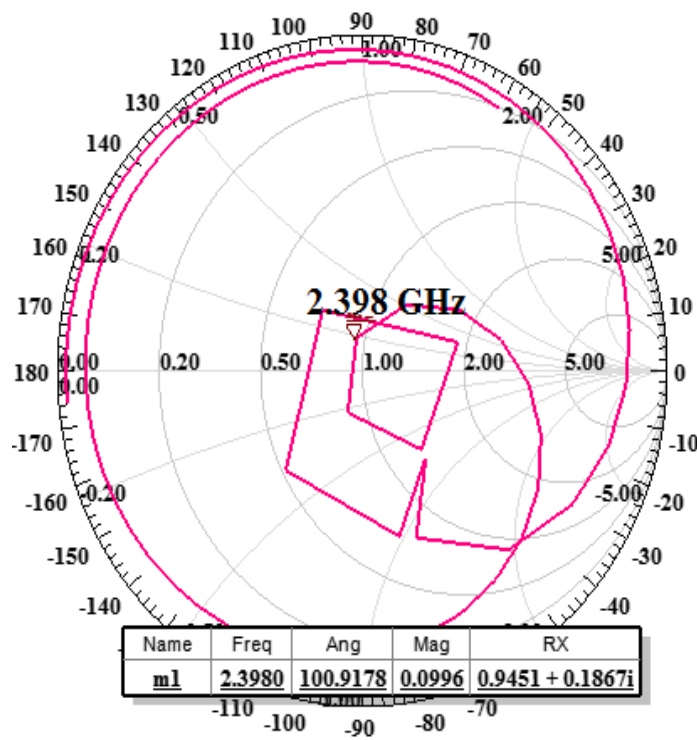

Fig. 8. Impedance matching plot 


\section{Measurement results of fabricated structure}

The proposed filtering antenna structure is fabricated using FR4_epoxy substrate material for $1.6 \mathrm{~mm}$ substrate thickness. The fabricated structure is then tested using a vector network analyzer which is calibrated suitably using the calibration kit that includes short, open and matched loads. The measured response is recorded for the return loss characteristics and the comparison plot is made for the simulated and fabricated responses as shown in Fig. 9. Thus, our fabricated structure also resulted in fine characteristics similar to the simulated curve achieving a bandwidth of about 200MHz [Table VI].

Table-VI:Comparison value of simulated and fabricated responses

\begin{tabular}{|c|c|c|}
\hline Design & $\begin{array}{l}\text { Return } \\
\text { loss }\end{array}$ & Bandwidth \\
\hline Simulated result & $-20 \mathrm{~dB}$ & 209 MHZ \\
\hline Fabricated result & $-26 \mathrm{~dB}$ & $200 \mathrm{MHZ}$ \\
\hline
\end{tabular}

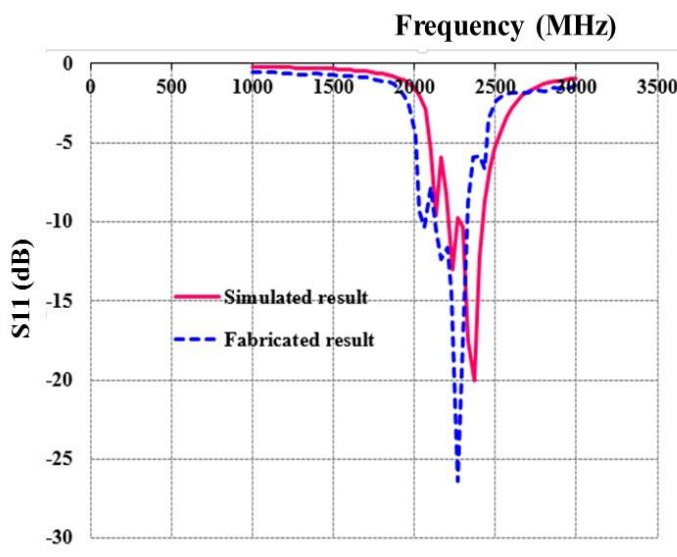

Fig. 9. Comparison of simulated and fabricated responses

The snapshot of the proposed fabricated filtering antenna structure is shown in Fig. 10.

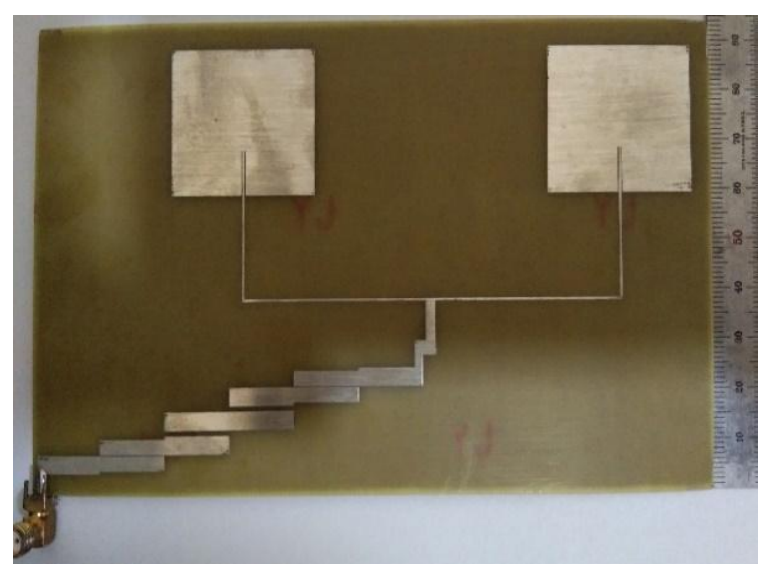

Fig. 10. Photograph of the fabricated filtering antenna structure

Finally, a comparison of the proposed filtering antenna structure is done with the other works mentioned in the literature and it is shown in Table VII. Even though different types of filtering antenna structures have been implemented, only a few papers focussed on integrating parallel coupled resonators and the patch antenna array. Our proposed structure helped to achieve significant improvement in the bandwidth (BW) of about $209 \mathrm{MHz}$, considerable return loss (RL) of about $-20 \mathrm{~dB}$, and an optimum gain of $1.53 \mathrm{~dB}$, and also rejected unwanted frequency bands.

Table-VII: Comparison with other research works

\begin{tabular}{|c|c|c|c|c|c|c|c|}
\hline $\begin{array}{l}\text { Re } \\
\text { f } \\
\text { No } \\
.\end{array}$ & $\begin{array}{c}\text { Freq } \\
\text { (GHz } \\
\quad)\end{array}$ & $\begin{array}{c}\text { Anten } \\
\text { na } \\
\text { Type } \\
\text { and } \\
\text { filter }\end{array}$ & $\begin{array}{c}\text { Size } \\
\left(\lambda_{\mathrm{g}} \mathbf{x} \lambda_{\mathrm{g}}\right)\end{array}$ & $\begin{array}{c}\text { BW } \\
\text { (M } \\
\text { Hz) }\end{array}$ & $\begin{array}{l}\mathbf{R} \\
\mathbf{L} \\
\text { (d) } \\
\text { B) }\end{array}$ & $\begin{array}{c}\text { Ord } \\
\text { er } \\
\text { of } \\
\text { the } \\
\text { filte } \\
\text { r } \\
\end{array}$ & $\begin{array}{l}\text { G } \\
\text { ai } \\
\mathbf{n} \\
(\mathbf{d} \\
\mathbf{B i} \\
) \\
\end{array}$ \\
\hline [6] & 5 & $\begin{array}{l}2 \times 2 \\
\text { Micros } \\
\text { trip } \\
\text { patch } \\
\text { array } \\
\text { and } \\
\text { hair } \\
\text { pin } \\
\text { resonat } \\
\text { or }\end{array}$ & $\begin{array}{c}1.72 \times 1 \\
.48\end{array}$ & 200 & $\begin{array}{c}-2 \\
0\end{array}$ & 3 & $\begin{array}{l}6 . \\
5\end{array}$ \\
\hline [8] & 2.4 & $\begin{array}{c}\text { Inverte } \\
\mathrm{d} \mathrm{L} \\
\text { and } \\
\text { paralle } \\
1 \\
\text { couple } \\
\mathrm{d} \\
\text { resonat } \\
\text { or } \\
\end{array}$ & $\begin{array}{c}0.9 \times 1 \\
05\end{array}$ & 150 & $\begin{array}{c}-1 \\
0\end{array}$ & 2 & $\begin{array}{l}0 . \\
65\end{array}$ \\
\hline $\begin{array}{l}{[10} \\
]\end{array}$ & 5 & $\begin{array}{l}\text { U-Sha } \\
\text { ped } \\
\text { patch } \\
\text { and } \\
\text { T-type } \\
\text { resonat } \\
\text { or } \\
\end{array}$ & $\begin{array}{c}0.46 \times 0 \\
.5\end{array}$ & 200 & $\begin{array}{c}-2 \\
0\end{array}$ & 1 & $\begin{array}{l}2 . \\
5\end{array}$ \\
\hline $\begin{array}{l}{[12} \\
]\end{array}$ & 3 & $\begin{array}{l}\text { Rectan } \\
\text { gular } \\
\text { patch } \\
\text { and } \\
\text { End-E } \\
\text { nd } \\
\text { couple } \\
\text { d } \\
\text { resonat } \\
\text { or } \\
\end{array}$ & $\begin{array}{c}0.87 \times 0 \\
.41\end{array}$ & 100 & $\begin{array}{c}-3 \\
0\end{array}$ & 5 & $\begin{array}{l}3 . \\
5\end{array}$ \\
\hline
\end{tabular}




\begin{tabular}{|c|c|c|c|c|c|c|c|}
\hline $\begin{array}{l}{[15} \\
]\end{array}$ & 2 & $\begin{array}{c}\text { Rectan } \\
\text { gular } \\
\text { patch } \\
\text { and } \\
\text { Hairpi } \\
\text { n } \\
\text { resonat } \\
\text { or }\end{array}$ & $\begin{array}{c}1.07 \times 1 \\
.14\end{array}$ & 80 & $\begin{array}{l}-3 \\
5\end{array}$ & 3 & 4 \\
\hline $\begin{array}{l}{[17} \\
]\end{array}$ & 2.45 & $\begin{array}{l}\text { Hairpi } \\
\mathrm{n} \\
\text { resonat } \\
\text { or and } \\
\text { patch } \\
\text { antenn } \\
\text { a }\end{array}$ & $\begin{array}{c}1.65 \times 0 \\
.52\end{array}$ & 50 & $\begin{array}{c}-1 \\
5\end{array}$ & 3 & -- \\
\hline $\begin{array}{l}\text { Thi } \\
\text { s } \\
\text { wo } \\
\text { rk }\end{array}$ & 2.4 & $\begin{array}{c}1 x 2 \\
\text { Rectan } \\
\text { gular } \\
\text { Patch } \\
\text { array } \\
\text { and } \\
\text { paralle } \\
1 \\
\text { couple } \\
\text { d } \\
\text { resonat } \\
\text { or }\end{array}$ & $\begin{array}{c}2.81 \times 1 \\
.5\end{array}$ & 209 & $\begin{array}{c}-2 \\
0\end{array}$ & 3 & $\begin{array}{l}1 . \\
53\end{array}$ \\
\hline
\end{tabular}

\section{CONCLUSION}

The design, simulation and fabrication of the filtering antenna structure suitable for S-Band wireless applications is proposed in this work. The designed antenna array structure acts both as a radiating element and also as the last resonator of the band pass filter. The integration of the filter and antenna not only helps to obtain a compact structure but also decreases the cost of the communication system. Through our novel configuration, we could simultaneously observe out-of-band rejection, wider bandwidth of about $209 \mathrm{MHz}$ and better frequency selectivity. The structure also shows good agreement between the simulated and fabricated responses. Our future work is to design a filtering antenna with enhanced bandwidth and gain by using a well optimized design.

\section{REFERENCES}

1. M. Kufa, Z. Raida, P. Vsetula et al, "Filtering Antennas: Comparison of Different Concepts", IEEE-APS Topical Conference on Antennas and Propagat.Wireless Communication, 2014, pp. 438-441.

2. Alaa, I. Abunjaileh, Ian, C. Hunter and Andrew, H. Kemp, "A Circuit Theoretic Approach to the Design of Quadruple- Mode Broadband Microstrip Patch Antennas," IEEE Trans. Microwave Theory Tech., vol.56, No.4, Apr. 2008, pp.896-900.

3. F. Queudet, I. Pele, B. Froppier, Y. Maheand S. Toutain, "Integration of Pass-Band Filters inPatch Antennas" in Proc. 32nd European Microwave Conf., Sep. 2002, pp. 685-688.

4. N. Yang, C. Caloz and K. Wu, "Co-designed CPS UWB Filter-Antenna System," in Proc. IEEE Antennas Propagat., Soc. Int. Symposium, Jun. 2007, pp.1433-1436,

5. F. Queudet, B. Froppier, Y. Mahe and S. Toutain, " Study of a Leaky Waveguide for the Design of Filtering Antennas," in Proc. of 33th European Microwave Conf., Oct. 2003, pp.943-946.
6. Chin-Kai Lin and Shyh-Jong Chung, "A Filtering Microstrip Antenna Array”, IEEE Trans. Microwave Theory and Techn.,vol.59, No.11, Nov. 2011, pp. 2856-2863.

7. S. Oda, S. Sakaguchi, H. Kanaya, Pokharel and K. Yoshida, "Electrically Small Superconducting Antennas with Bandpass Filters", IEEE Trans. Applied Superconductivity, vol.17, No.2, Jun. 2007, pp. 878-881.

8. Chao-Tang and Shyh-Jong Chung, "Synthesis and Design of a New Printed Filtering Antenna", IEEE Trans. Antennas Propagat., vol.59, No.3, Mar. 2011, pp. 1036-1042.

9. Chao- Tang Chuang and Shyh-Jong Chung, " A Compact Printed Filtering Antenna Using a Grounded-Intruded Coupled Line Resonator", IEEE Trans. Antennas Propagat., vol.59, No.10, Oct. 2011, pp. 3630-3637.

10. Chin-Kai Lin and Shyh-Jong Chung, "A Compact Filtering Microstrip Antenna with Quasi- Elliptic Broadside Antenna Gain Response", IEEE Antennas Wireless Propagat. Letters, vol.10, Apr. 2011, pp.381-384.

11. Xinwei Chen, Fengxian Zhao, Liyun Yan and Wenmei Zhang, "A Compact Filtering Antenna with Flat Gain Response Within the Passband", in Proc. IEEE Antennas and Wireless Propagat., Letters, Vol. 12, Jul. 2013, pp. 857-860.

12. Xiaobang Shang, Michael, J. Lancaster, "Patch Antenna with Integrated Bandpass Filter", 4th Annual Seminar on Passive RF and Microwave Components, Mar.2013, pp.1-5.

13. A. AbbaspourTamijani, J. Rizk and G. Rebeiz, "Integration of Filters and Microstrip Antennas," in Proc. IEEE Antennas and Propagat. Soc. Int. Symposium., Jun. 2002, pp. 874-877.

14. T. Manikandan, R. Kanagavalli, B. Kavitha, J. Mutharasi, M. Sathish, "Design and development of Patch Antenna Array with Band-pass filter for ISM band applications", in Proceedings of ${ }^{\text {rd }}$ Intern. Conf. Electronics Communication and Aerospace Technology, ISBN: 97817281-0167-5, 2019, pp.888-891.

15. Ghaith Mansour, Michael, J. Lancaster, Peter, S. Hall, Peter Gardner and EkasitNugoolcharoenlap, " Design of filtering Microstrip Antenna using Filter synthesis Approach," Prog. Electromagnetic Research, vol. 145, Feb. 2014, pp. 59-67.

16. Hongming An, Bart, K. J. C. Nauwelaers and Antoine, R. Van de Capelle, "Broadband Microstrip Antenna Design with the Simplified Real Frequency Technique," IEEE Trans. Antennas and Propagat.,vol.42, No.2, Feb 1994, pp. 129-136.

17. Alberto hueltes., Jordi verdu., Carlos collado., et al. Filtenna Integration Achieving Ideal Chebyshev Return losses. Radio Engineering, 2014, vol. 23, No. 1, pp. 362-368.

18. R.Srilakshmi, T.Manikandan and Shaikh ThasleemBanu, "Performance Comparision of S-Band Antenna Array with Series fed and Corporate fed Microstrip Array", Int. J. Engineering and Technology, vol.7(2.33), 2018, pp. 1036-1039.

19. Ansys High Frequency Structure Simulation (HFSS), [Available online]. www.ansys.com

20. J. S. Hong and M.J. Lancaster, "Microstrip Filters for RF/Microwave Applications", 2nded. Hoboken, NJ, USA: Wiley and Sons, 2011.

21. M. Ansarizadeh and A. Ghorbani, "An Approach to Equivalent Circuit Modeling of Rectangular Microstrip Antennas”, Prog. Electromag. Research, vol. 8, Jan. 2008, pp. 77-86.

22. Fan Yang, Xue-Xia Zhang, Xiaoning Ye and YahyaRahmat-Samii, "Wide-Band E-Shaped Patch Antennas for Wireless Communications", IEEE Trans. Antennas Propagat., vol.49, No.7 Jul. 2001, pp. 1094-1100.

23. V. Nandalal, V. Anand Kumar, T. Manikandan, “ Performance Evolution of Reconfigurable Antenna using Contact and Non-Contact feeding Technique", in Proc. of $3^{\text {rd }}$ Int. Conf. Electronics Communication and Aerospace tech., ISBN: 978-1-7281-0167-5 2019, pp.952-954.

24. M. A. Matin and A. I. Sayeed, "A Design Rule for Inset-fed Rectangular Microstrip Patch Antenna", WSEAS Trans. Communications", Issue 1, ISSN: 1109-2742, vol. 9, Jan 2010, pp. 63-72. 


\section{AUTHORS PROFILE}

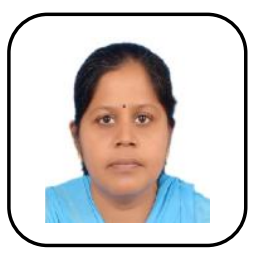

Srilakshmi $\mathbf{R}$ received the B.E. degree in Electronics and Communication Engineering from Bharathiar University, Coimbatore, India, in 2004, and the M.E degree in Communication Systems from the Anna University, Chennai, India, in 2006. She is currently working towards the full-time $\mathrm{Ph} . \mathrm{D}$. degree in Information and Communication engineering from Anna University, Chennai, India. She has publications in national and international journals. Her research interests include filtering antennas, microstrip filters and antenna design for wireless applications.

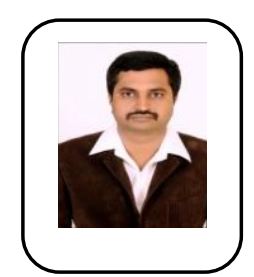

Dr. T. Manikandan is a Professor working at Rajalakshmi Engineering College, Thandalam, Chennai. He has completed his Ph.D titled "A study on computer-aided diagnosis systems for lung cancer detection and its three dimensional visualization using machine learning techniques" at Anna University, Chennai during January, 2017. He did his bachelor's degree in Engineering from Vellore Engineering College, Chennai under Madras University \& master's degree in Engineering from College of Engineering, Anna University, Guindy, Chennai during 1998 \& 2007, respectively. He is having 20 years of teaching experience which includes both UG and PG. He also guided many projects at UG \& PG levels. He has 50 papers in refereed international journals and conferences in his credit. He is serving as editorial board member for various international journals such as International journal of Biomedical and Healthcare Sciences, Archives of General Internal Medicine, Journal of Cancer Diagnosis, Journal of Medical and Clinical Oncology, Journal of Clinical Epigenetics and Integrative Cancer Biology and Research. 